\title{
Thermal and Nanoindentation Behaviours of Layered Silicate Reinforced Recycled GF-12 Nanocomposites
}

\author{
A. Shalwan ${ }^{1}$, A. I. Alateyah ${ }^{2}$, B. Aldousiri ${ }^{3} \&$ M. Alajmi ${ }^{1}$ \\ ${ }^{1}$ Manufacturing Engineering Technology Department, College of Technological Studies, Public Authority for \\ Applied Education and Training, Kuwait City 13092, Kuwait \\ ${ }^{2}$ Mechanical Engineering Department, Qassim University, P.O.B.6677, Buraydah, Saudi Arabia \\ ${ }^{3}$ Advanced Polymer and composites (APC) Research Group, Department of Mechanical \& Design Engineering, \\ University of Portsmouth, PO1 3DJ, UK \\ Correspondence: A. Shalwan, Manufacturing Engineering Technology Department, College of Technological \\ Studies, Public Authority for Applied Education and Training, Kuwait City 13092, Kuwait. Tel: 965-22-314-853. \\ E-mail: ama.alajmi1@paaet.edu.kw
}

Received: July 9, 2016

doi:10.5539/jmsr.v5n4p10
Accepted: July 25, 2016

Online Published: August 27, 2016

URL: http://dx.doi.org/10.5539/jmsr.v5n4p10

\begin{abstract}
This work is an attempt to improve the thermal and nanoindentation behaviours of recycled Glass-Filled Polyamide-12 (GF-12) by adding layered Silicate (Nanoclay) as a reinforced filler. Differential Scanning Calorimetry (DSC) and Nanoindentation tests were conducted to study the effect of various loading levels (0-7 wt. \%) of Nano-layered silicate on the thermal and nanohardness behaviours of GF-12 and its nanocomposites. Wide Angle X-ray Diffraction (WAXD) was employed to characterise the nanostructure of material and determine the intercalation/exfoliation for layered silicate in a GF-12 matrix. This study reveals that the layer silicate has a positive effect on the hardness results. Nanoindentation results showed remarkable improvement when layered silicate was added to recycled GF-12. The Glass transition $\left(\mathrm{T}_{\mathrm{g}}\right)$ and crystallization $\left(\mathrm{T}_{\mathrm{c}}\right)$ temperatures showed a slight improvement over the base polymer by the incorporation of layered silicate. Moreover, the enhancement of crystallization was obvious with the addition of clay loading, which functioned as a nucleating agent that could increase the rate of crystallization.
\end{abstract}

Keywords: Nanocomposites, polymers, Differential Scanning Calorimetry (DSC), nanoindentation

\section{Introduction}

Polymer nanocomposites (PNCs) have recently emerged as substitutes for conventional materials and have aroused considerable interest for their use in numerous industrial applications, such as automobiles, food packaging and rapid manufacturing (RM) (Aldousiri, Shalwan, \& Chin, 2013; Alexandre \& Dubois, 2000; Fischer, 2003; Sinha Ray \& Okamoto, 2003; Youssef, 2013). This is mainly due to the superior properties of PNCs in mechanical, thermal, physical and chemical terms to conventional composite materials. They have greater tensile strength, impact resistance, elastic modulus, flexural strength, heat resistance and chemical resistance (Shalwan \& Yousif, 2013; Thomas \& Pothan, 2009; Youssef, 2013).

As the literature shows, the enhancement of the PNCS' performance results from the ability of nanometer particles to disperse in a polymer matrix (Alexandre \& Dubois, 2000; Fischer, 2003; Kiliaris \& Papaspyrides, 2010; Shalwan \& Yousif, 2014). In other words, the performance of PNCs greatly depends on the characteristics of nanometer particles and the structural characterisation of nanocomposites, for instance their microcomposite, intercalated or exfoliated structure. In this context, layered silicate has shown remarkable performance as an additive to polymers, which has led to the enhancement of its mechanical and thermal properties, due to the capacity of the silicate to separate or break down into individual layers (Djebara, El Moumen, Kanit, Madani, \& Imad, 2016; Kotal \& Bhowmick, 2015; Liu, Ping Lim, Chauhari Tjiu, Pramoda, \& Chen, 2003). Many investigators have investigated the production of new nanocomposite materials with improved mechanical and thermal properties (Djebara et al., 2016; Hu et al., 2006; Liu et al., 2003; Yu, Zhao, Chen, Juay, \& Yong, 2007; Zeng, Yu, Lu, \& Paul, 2005). For example, Liu et al. (Liu et al., 2003) studied the mechanics of Nylon 11/organoclay nanocomposites containing $(0,1,2,4$ and 8 wt.\%) organoclay. Dynamic Mechanical Analyser 
(DMA) tests showed that the storage modulus noticeably increased by $100 \%$ when the clay loading went up to 8 wt. \%, compared with the neat Nylon 11.

In addition, $\mathrm{Hu}$ et al. ( $\mathrm{Hu}$ et al., 2006) used the nanoindentation technique to investigate the mechanical properties (i.e. hardness and modulus) of Nylon 11 and its nanocomposites. It was found that the hardness and modulus of the nanocomposites steadily increased with increasing clay content. With the inclusion of 5 wt. \% clay into the PA11 matrix, the hardness and elastic modulus were improved by about 30\%. Moreover, Shen et al. (Shen, Phang, Liu, \& Zeng, 2004) investigated the mechanical properties of PA66/clay nanocomposites using the nanoindentation technique. It was obvious that the hardness and the elastic modulus were gradually enhanced with increasing clay concentration. Moreover the creep behaviour of the nanocomposites was considerably increased by increasing the clay content. In addition, Shen et al.(Shen, Tjiu, \& Liu, 2005) studied the nanoindentation behaviour of PA6/clay. It was clear that the modulus and hardness of the nanocomposites with 2.5 wt. $\%$ of clay were enhanced by $74 \%$ and $80 \%$, respectively compared with the neat PA6.

Likewise, Aldousiri et al.(Aldousiri, Dhakal, Onuh, Zhang, \& Bennett, 2011) carried out a study of the nanoindentation of spent polyamide-12 and the PA-12/nanocomposite. It was found that the addition of layered silicate led to increases of up to $116 \%$ and $73 \%$, respectively of $n$ ano-hardness and modulus, compared to the unreinforced polymer. The authors attributed the enhancement in properties to the changes in the properties matrix caused by the high aspect ratio of layered silicate.

However, characterizing and studying the structures of nanocomposites is considered the first step in understanding the behaviour of nanocomposites. X-ray diffraction (XRD) and wide angle X-ray diffraction (WAXD) are the most widely used techniques for evaluating nanocomposite systems (Hussain, Hojjati, Okamoto, \& Gorga, 2006). In addition, the XRD method provides an understanding of the distances between the layers in the silicates structure, using Bragg's Law (Alexandre \& Dubois, 2000). The degree of dispersion of the nanoclay in the polymer can be discovered by using XRD technique to determine the d-spacing in nanocomposite material (Giannelis, 1996).

Any improvement in thermal properties will also give nanocomposites many more opportunities to be applied industrially, in the construction and automotive sectors, for example (Pinnavaia, 2000; Yu et al., 2007; Zeng et al., 2005). Suzhu et al. (Yu et al., 2007) found that layered-silicate loading was affected in the crystalline and thermal behaviors of polyamide layered-silicate nanocomposites. Moreover, layered-silicates have led to slight reductions in the crystalline and melting temperature of polyamide layered-silicate nanocomposites.

Selective Laser Sintering (SLS) is one of the rapid prototyping techniques that are commonly used in Rapid Manufacturing to build parts from powder. A wide range of polymers can be used in this process, such as thermoplastic polymers (polyamide, polycarbonate), which can be used to manufacture aerospace products and the automotive and packaging industries. However, those products which are wasted in the processing must in the end be replaced by new products made from virgin raw materials and the disposal of the old products can represent a serious environmental issue.

This paper reports on a study of the effect of various loading levels of Nano-layered silicates used to reinforce the thermal and nanoindentation behaviours of recycled Glass-Filled Polyamide- 12.

\section{Experimental}

\subsection{Materials}

In this experiment, Recycled Glass-filled Polyamide-12 (GF-12) was used as the matrix material (mix ratio 45 wt.\% virgin, 55 wt.\% recycled) provided by the Centre for Rapid Design and Manufacturing (CRDM), Buckinghamshire, U.K. Glass-filled polyamide-12 is widely used in Selective Laser Sintering (SLS). The filler material used was Nano-layered Silicate, commercially known a LK-PA-CR1. Both polymer and filler were supplied as fine white powders with particles of similar size (RGF $\approx 48 \mu \mathrm{m}, \mathrm{LK}-\mathrm{PA}-\mathrm{CR} 1 \approx 50 \mu \mathrm{m})$.

\subsection{Sample Preparation}

The Recycled Glass-filled Polyamide-12 (GF-12) and Nano-layered Silicate were dried separately in a fan assisted oven at $100{ }^{\circ} \mathrm{C}$ for $1 \mathrm{~h}$ in order to remove the residual moisture, because both these materials absorb water. A dry grinding process was employed to mix various weight percentages (3, 5 and 7 wt. \%) of Nano-layered Silicate with GF-12, using a high speed rotary Kenwood blender at a rotary speed of $800 \mathrm{rpm}$ for 10 min. Test specimens were prepared using an MCP Mini Moulder 12/90 HSP with a temperature profile of $240^{\circ}-260^{\circ} \mathrm{C}$ with a screw speed of $200 \mathrm{rpm}$. 


\subsection{Wide Angle X-ray Diffraction (WAXD)}

Injection moulded samples were examined and analysed using the wide angle X-ray diffraction technique to verify clay dispersion and characterise the nanostructure of the material. WAXD analysis was performed using a Philips X-ray diffractometer with $\mathrm{Cu}$ Ka radiation generated $(\lambda=1.542)$ at $20 \mathrm{~mA}$ and $40 \mathrm{kV}$. The d-spacing values (i.e. the values of the basal distance between the clay layers) were calculated using Bragg's Law:

$$
n \lambda=2 d \sin \theta
$$

where $\mathrm{n}$ is an integer, $\mathrm{d}$ is the inter layer $\mathrm{d}$-spacing and $\lambda$ is the wave length.

\subsection{Differential Scanning Calorimetry (DSC)}

DSC measurements were employed to investigate the effect of the layered silicates on the melting and crystallization behavior. Samples of recycled GF-12 and GF-12/nanocomposites were studied using TA Instruments. The encapsulated sample pan and an empty reference pan were positioned inside a DSC machine and heated and cooled at the rate of $20{ }^{\circ} \mathrm{C} / \mathrm{min}$ up to $250{ }^{\circ} \mathrm{C}$. The specimen for the DSC test was in the form of powder obtained by scraping the bulk sample with a knife. The sample mass was approximately $10 \mathrm{mg}$. The DSC test was made in an inert nitrogen atmosphere. A minimum of three samples were used in this test and the standard deviation was determined for each group.

\subsection{Nanoindentation Testing}

The Nanoindentation tests were carried out in a NanoTest apparatus (Micro Materials, UK) as shown in Figure 1. A Berkovich diamond indenter tip manufactured by Micro Materials was used to measure the nanohardness properties. Nine symmetrical indentations (in the form of a matrix, $30 \mu \mathrm{m}$ apart) were made on each specimen. The Nanoindentation specimens were prepared by injection moulding and then cut into pieces sized approximately $15 \times 15 \times 3 \mathrm{~mm}$.

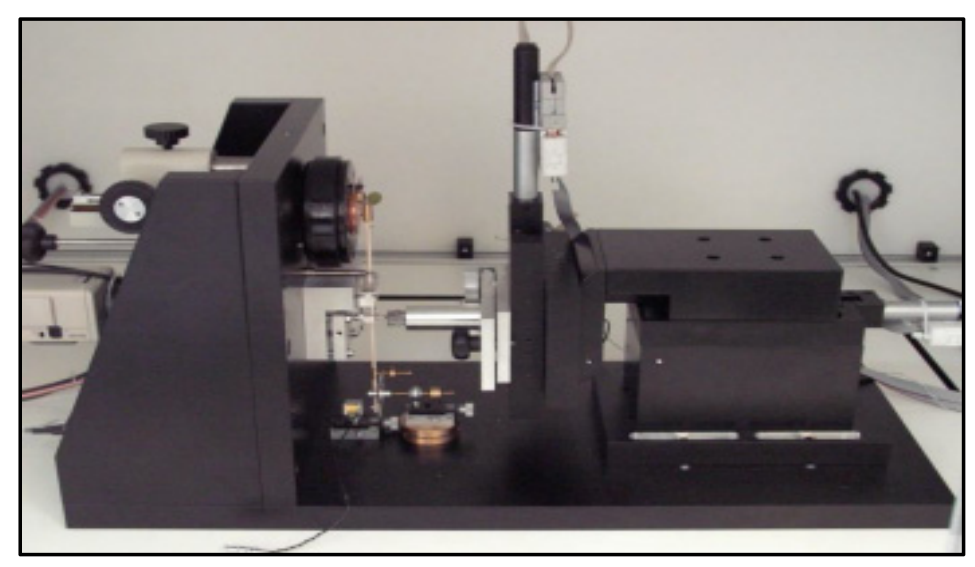

Figure 1. Schematic view of the NanoTest system

The parameters used for all measurements were as follows:

Initial load: $0.1 \mathrm{mN}$

Maximum load for all indents: $3.2 \mathrm{mN}$

Loading and unloading rate (strain rate): $2.00 \mathrm{mN} \mathrm{S}^{-1}$

Dwell time or holding time at maximum load: $5 \mathrm{~s}$

Hardness and elastic modulus measurement

In indentation testing, the hardness is defined as the indentation load divided by the projected contact area. The hardness $(H)$ is determined from the peak load $\left(P_{\max }\right)$ and the projected area of contact $(A$,$) using the empirical$ relation:

$$
H=\frac{P_{\max }}{A}
$$


To obtain the elastic modulus, the unloading portion of the depth-load curve is analyzed according to a relation, which depends on the contact area, as explained elsewhere [11,12]. The indentation modulus E indent can be calculated from the slope of the tangent for the calculation of indentation hardness and is comparable to Young's modulus of materials. The theoretical modulus was calculated by Equation (3) [10]:

$$
E_{\text {indent }}=\frac{1-\left(v_{S}\right)^{2}}{\frac{1}{E_{r}}-\frac{1-\left(v_{i}\right)^{2}}{E_{i}}}
$$

$\mathrm{V}_{\mathrm{s}}$ Poisson's ratio of the test piece; (for polymer approximately 0.2)

$v_{i}$ Poisson's ratio of the indenter (for diamond 0.07)

$E_{i}$ Young's modulus for the indenter (for a diamond $1141 \mathrm{GPa}$ ).

$\mathrm{E}_{\mathrm{r}}$ Modulus of the indentation contact (reduced modulus)

\section{Result and Discussion}

\subsection{Wide Angle X-ray Diffraction (WAXD)}

Figure 2 shows the results for the nanoscale dispersion of layered silicate in the GF-12 and GF-12/nanocomposites obtained by wide angle x-ray diffraction. The peak position of WAXD was used to calculate the interlayer distances of samples, the distance between the basal layers of nanoclay. Specifically, the d-spacing values were calculated using Bragg's Law for all theGF-12 and GF-12/nanocomposite samples; they summarised in Table 1.

It can be concluded that whenever the angle of the X-ray beam decreases, the spacing between the silicate layers grows, which could indicate enhancement of the ability of polymers to move in between the layers of silicate in the nanocomposite sample. In other words, the d-spacing value also indicates the degree of intercalation/exfoliation for the layered silicate in the polymer matrix. Many investigators have found that the d-spacing has a significant effect on and plays an important role in the ability of a polymer to enter between layers of clay. Put differently, $d$-spacing could be used to indicate the dispersion of clay into a polymer and to determine the structural level of the nanocomposite sample (whether an immiscible, intercalated or exfoliated nanocomposite structure) (Ginzburg, Singh, \& Balazs, 2000; Krishnamoorti, Vaia, \& Giannelis, 1996).

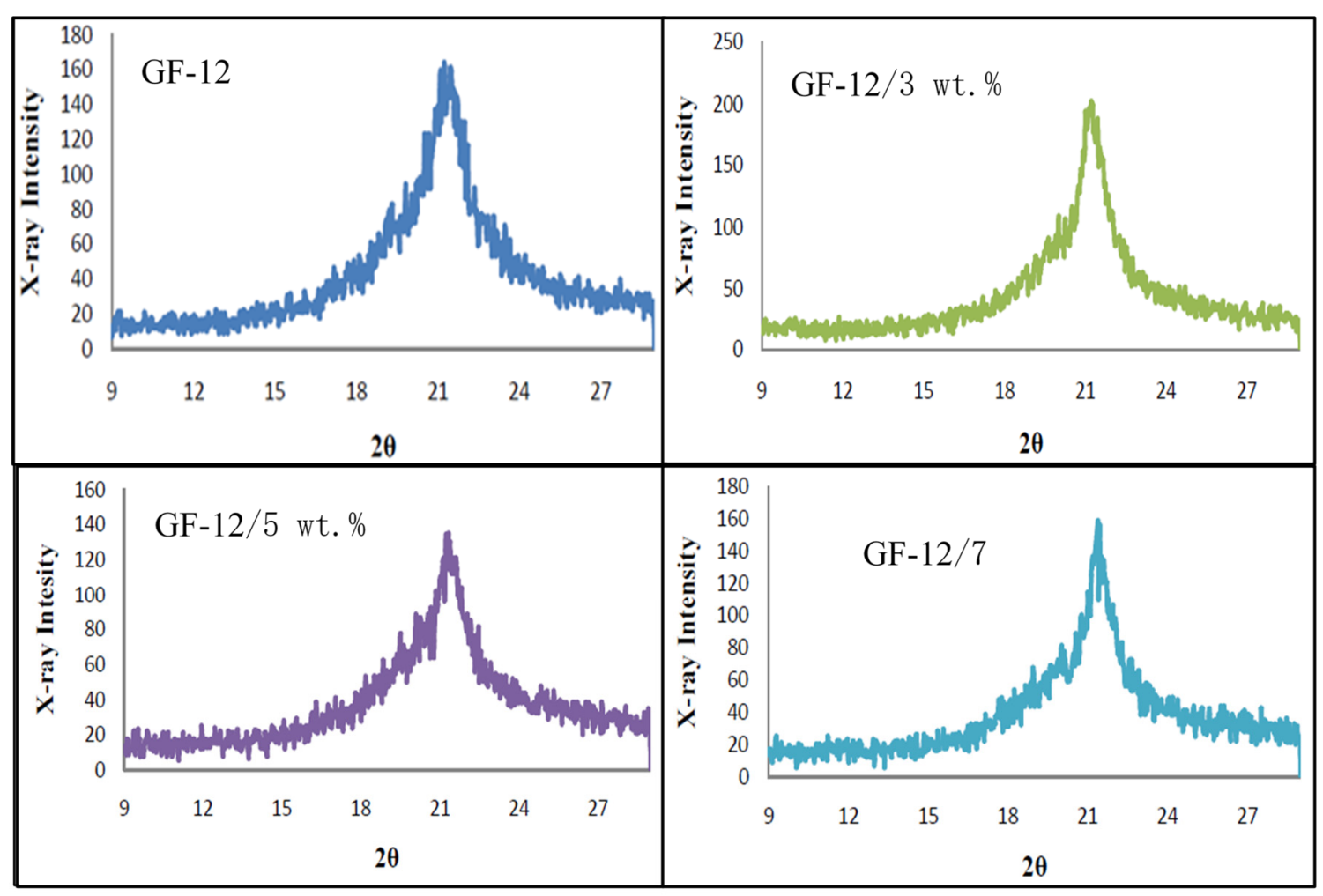

Figure 2. X-ray diffraction patterns for the GF-12 and GF-12 nanocomposites 
Table 1. WAXD results obtained from different clay loadings of nanocomposites

\begin{tabular}{lcccc}
\hline Specimen & RGP & RGPS /3wt.\% & RGPS /5wt.\% & RGPS /7 wt.\% \\
\hline $2 \theta$ value & 21.48 & 21.24 & 24.24 & 21.36 \\
d-spacing $(\mathrm{nm})$ & 4.13 & 4.18 & 4.18 & 4.15 \\
\hline
\end{tabular}

The peak positions, as shown in Figure 2, were obtained from X-ray diffraction to find the interlayer distance of each sample. For the un-reinforced GF-12 sample, the peak $2 \theta$ value position of the $2 \theta$ value was $21.48^{\circ}$ and the interlayer d-spacing value was $4.13 \mathrm{~nm}$. The peak $2 \theta$ values for $3 \%$ and $5 \mathrm{wt}$. $\%$ of the nanoclay loadings were $21.24^{\circ}$ and $21.24^{\circ}$ respectively and the inter layer $\mathrm{d}$-spacing values were 4.18 and $4.18 \mathrm{~nm}$, respectively. In the same way, for a $7 \mathrm{wt}$. \% nanoclay loading a $2 \theta$ value of $21.36^{\circ}$ and an interlayer d-spacing value of $4.15 \mathrm{~nm}$ were recorded. It can be concluded that as the angle in nanocomposite samples becomes smaller, the inter layer d-spacing increases and that this is related to the intercalated structures (Alexandre \& Dubois, 2000; Sinha Ray \& Okamoto, 2003).

\subsection{Differential Scanning Calorimetry (DSC)}

The DSC characterization method was used in to investigate the change in the glass transition temperature $\left(\mathrm{T}_{\mathrm{g}}\right)$ of the neat and corresponding nanocomposites as well as to study the effect on the crystallization $\left(T_{c}\right)$ and melting temperature $\left(T_{m}\right)$ of adding layered silicate to the polymer matrix. All the DSC results are shown in Figures 3-5 and summarized in Table 2. From the DSC results, it was found that the addition of layered silicate into the polymer matrix resulted in a slight improvement in the $\mathrm{T}_{\mathrm{g}}$, compared to the base polymer. As shown in Figure 3 , the neat matrix exhibited $47^{\circ} \mathrm{C}$ and for nanocomposites of $3 \%, 5 \%$, and 7 wt. $\%$ showed $47.20^{\circ} \mathrm{C}, 47.33^{\circ} \mathrm{C}$, and $47.50^{\circ} \mathrm{C}$ respectively. The improvement of $\mathrm{T}_{\mathrm{g}}$ can be attributed to the well dispersed layered silicate within the polymer matrix, which played an important part in increasing the $T_{g}$ results, as demonstrated by the results of XRD. When the amount of clay loading goes up, the $T_{g}$ goes down, compared to other wt. \% nanocomposites. This effect can be traced to the lower adhesion of the layered silicate and polymer matrix, in which the layered silicate does not insulate and protect the polymer matrix from heat, as shown in the values of XRD. Thus, the heat can easily reach the polymer matrix and increase the polymer's mobility. In addition, the formation of an interphase between the clay sheets can be important in reducing the $T_{g}$ value when the matrix material is close to the layered silicate surface. In turn, various properties from the bulk material are introduced. The phenomenon of interphase formation is attributed to the plasticization of the polymer surfactants (Alateyah, Dhakal, \& Zhang, 2013). Another explanation of the lower reduction of the $T_{g}$ value at a higher clay loading is the increased free volume of resin. In conclusion, it is worth mentioning that many factors can be important in changing the $T_{g}$ value, for example, the curing temperature and time, the modification of the layered silicate, and the intercalation level between sheets. The $T_{g}$ results were found to be in close agreement with the work reported in other studies (Alateyah, Dhakal, \& Zhang, 2014; Bakar, Kostrzewa, Hausnerova, \& Sar, 2010; Yasmin, Luo, Abot, \& Daniel, 2006).

The DSC test can also show important information about the crystallization and melting temperature by scan cycles of cooling and heating. As shown in Figures $4 \& 5$, up to 5 wt.\%, the improvement of crystallinity in the nanocomposites was almost proportional to the clay loading, but at higher clay loading, i.e. 7 wt.\%, a reduction of crystallinity was observed. The enhancement of the crystallinity value may be traced to the addition of layered silicate, which acts as a nucleating agent which can increase the rate of crystallization. The melting temperatures of the neat polymer and the nanocomposites were almost the same.

The GF-12 exhibited $177.63^{\circ} \mathrm{C}$. The nanocomposites samples of $3 \%, 5 \%$, and $7 \mathrm{wt} . \%$ showed $177.37^{\circ} \mathrm{C}, 177.21^{\circ}$ $\mathrm{C}$, and $177.47^{\circ} \mathrm{C}$ respectively. The crystallite size can be reduced by the addition of layered silicate, which in turn affects the melting temperature. This finding was in close agreement with the study by Kim and Creasy (Kim \& Creasy, 2004).

Table 2. DSC results for EX and its nanocomposites

\begin{tabular}{llll}
\hline Sample & $\operatorname{Tg}\left({ }^{\circ} \mathrm{C}\right)(\mathrm{SD})$ & $\mathrm{Tc}\left({ }^{\circ} \mathrm{C}\right)(\mathrm{SD})$ & $\mathrm{Tm}\left({ }^{\circ} \mathrm{C}\right)(\mathrm{SD})$ \\
\hline GF-12 & $47.00( \pm 0.12)$ & $152.80( \pm 0.22)$ & $177.63( \pm 0.09)$ \\
GF-12/ 3 wt. $\%$ & $47.20( \pm 0.10)$ & $154.20( \pm 0.13)$ & $177.37( \pm 0.1)$ \\
GF-12/ 5 wt. $\%$ & $47.33( \pm 0.11)$ & $155.19( \pm 0.14)$ & $177.21( \pm 0.12)$ \\
GF-12/ 7 wt.\% & $47.50( \pm 0.13)$ & $152.75( \pm 0.11)$ & $177.47( \pm 0.2)$ \\
\hline
\end{tabular}



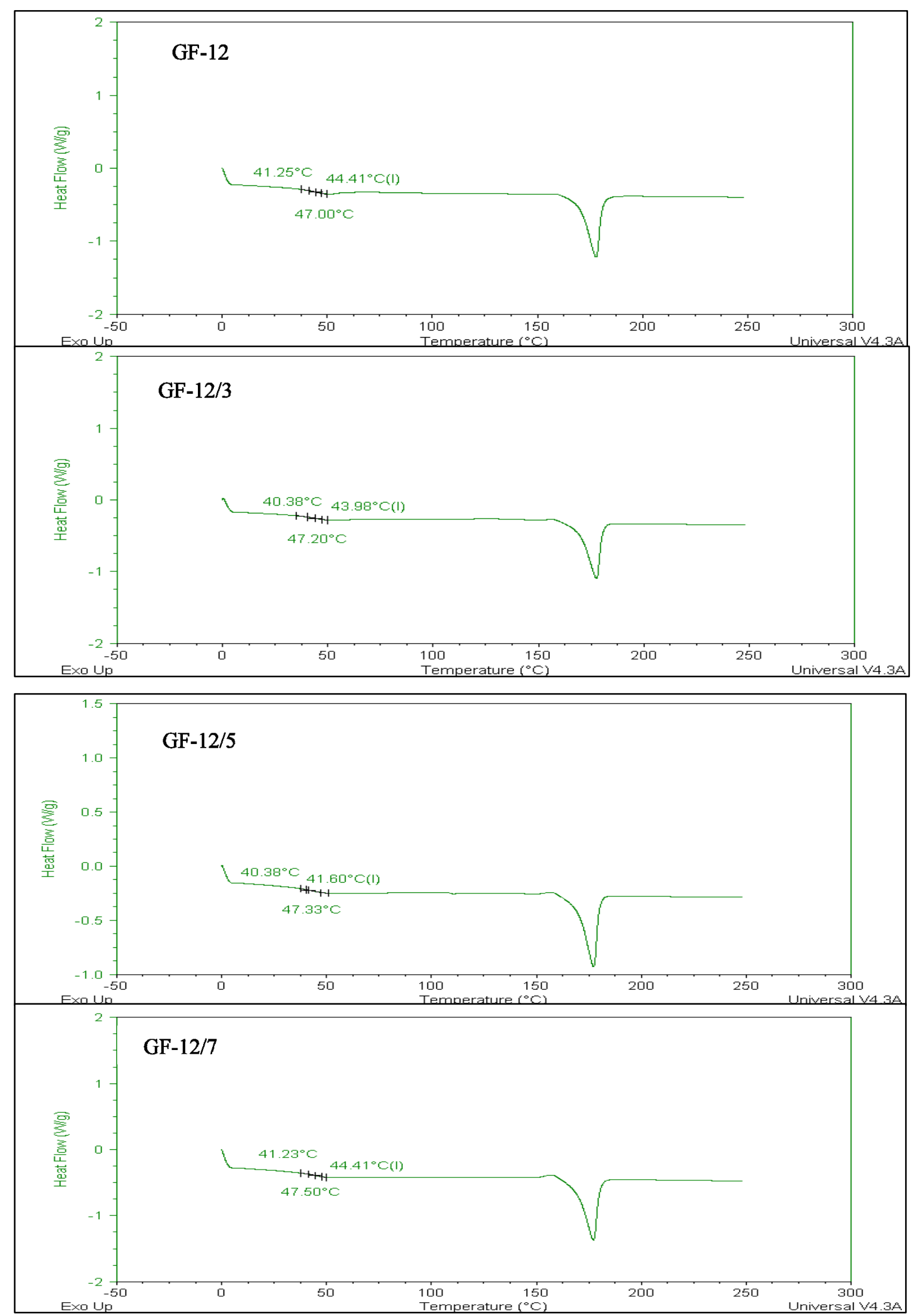

Figure 3. Glass Transition Temperature ( $\left.\mathrm{T}_{\mathrm{g}}\right)$ curve of the GF-12 samples 


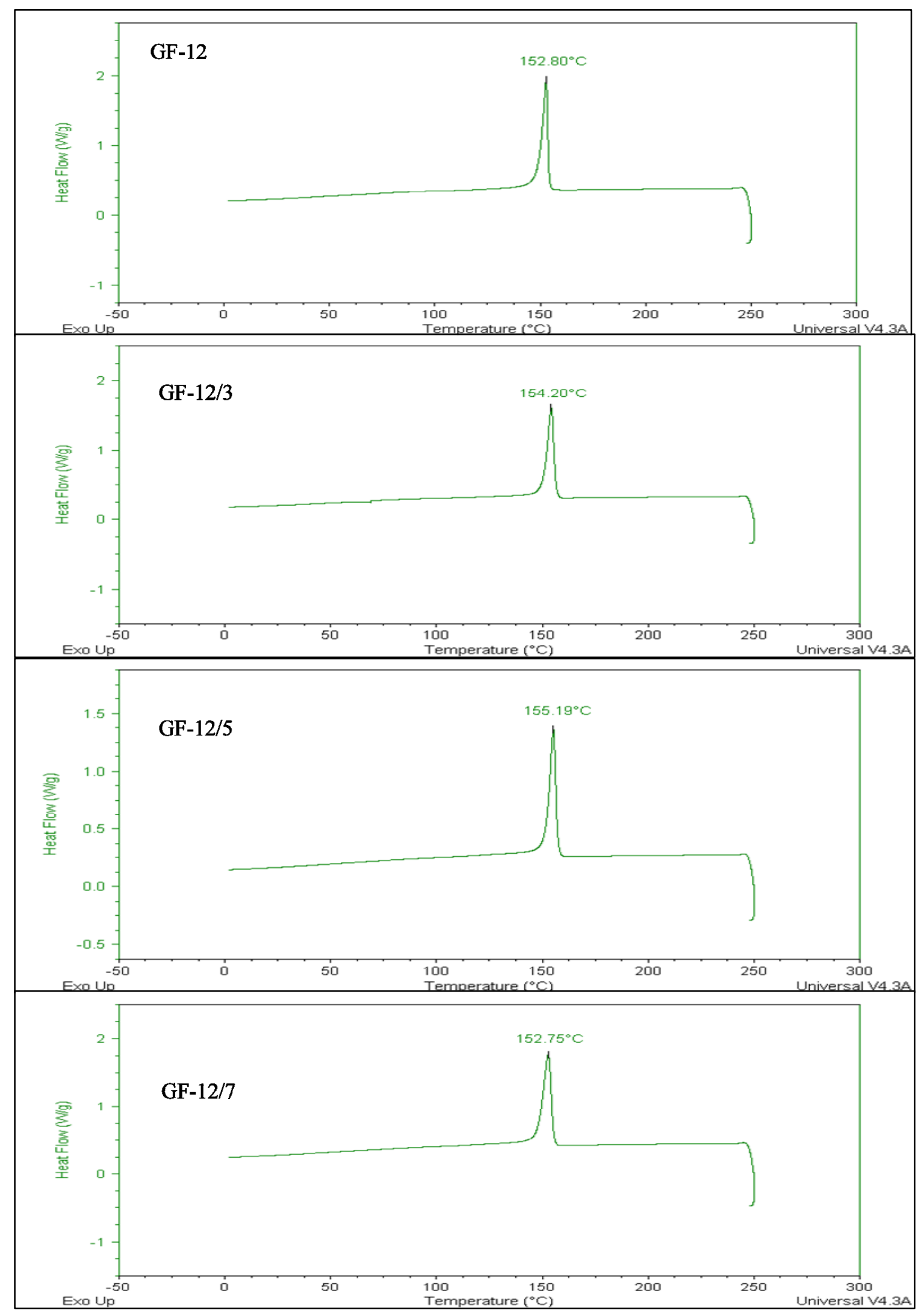

Figure 4. DSC cooling scans of the GF-12 samples 


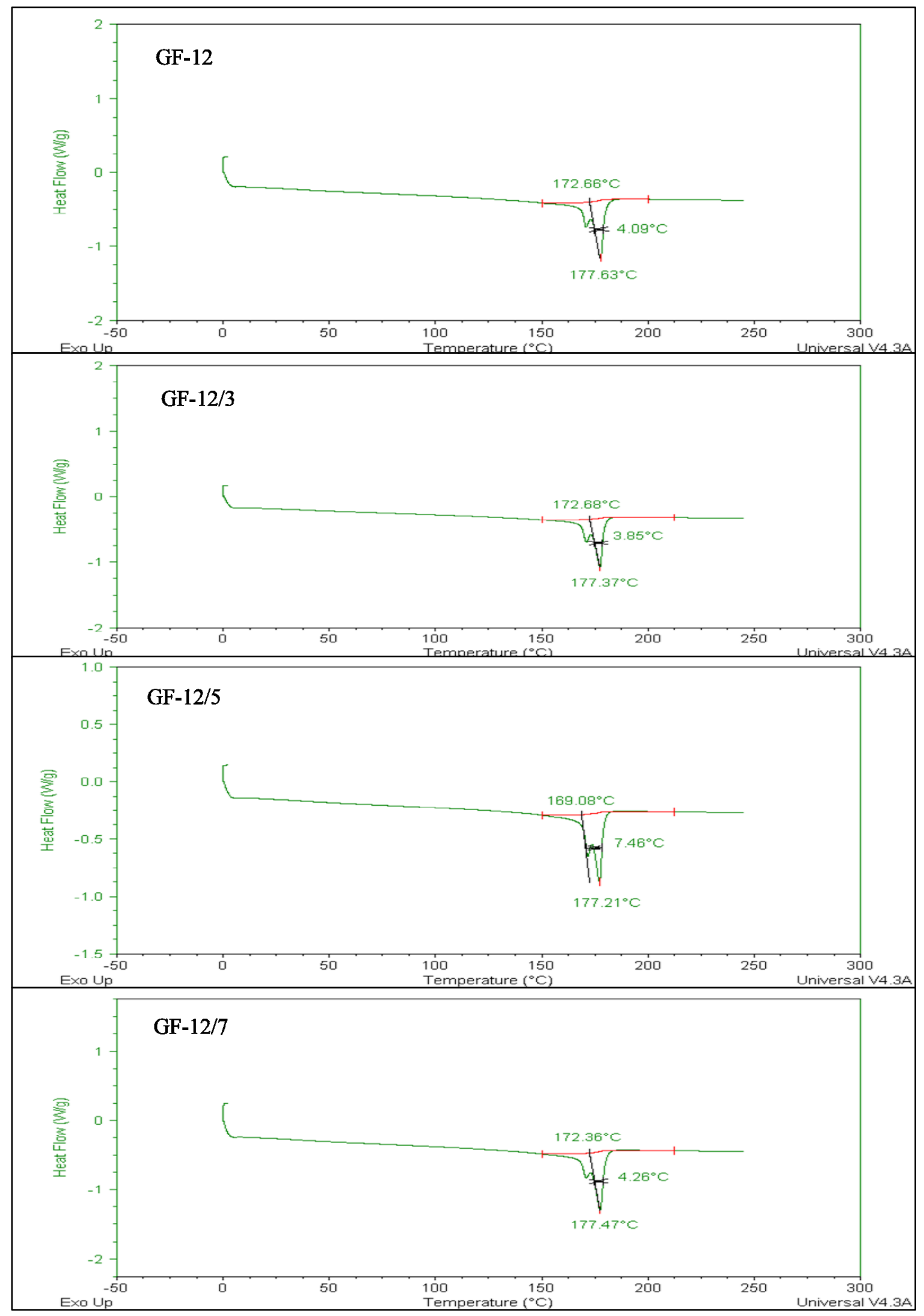

Figure 5. DSC heating curve of the GF-12 samples 


\subsection{Nanoindentation: Maximum Depth, Hardness and Elastic Modulus}

The average values of the experimental data extracted from the loading/unloading curves from the Nano-indentation tests are shown and summarized in Figures $6 \& 7$ and Table 3. As can be seen, with an increase in the layer silicate reinforcement, the materials' resistance to nanoindentation was found to increase monotonously.

The neat recycle GF-12 had the highest indentation depth $(1472 \mathrm{~nm})$; hence, it had the lowest hardness $(0.0922$ MPa). The depth at maximum load for 3\%, 5\% and $7 \mathrm{wt} \%$ nanocomposite samples were 1099, 1147 and $1007 \mathrm{~nm}$ respectively which were lower than the unreinforced recycle GF-12 sample, as can clearly be seen in Figure 6. At low/high levels of layered silicate, it can clearly be seen that the nanocomposite samples decreased in penetration depth compared to the unreinforced sample.

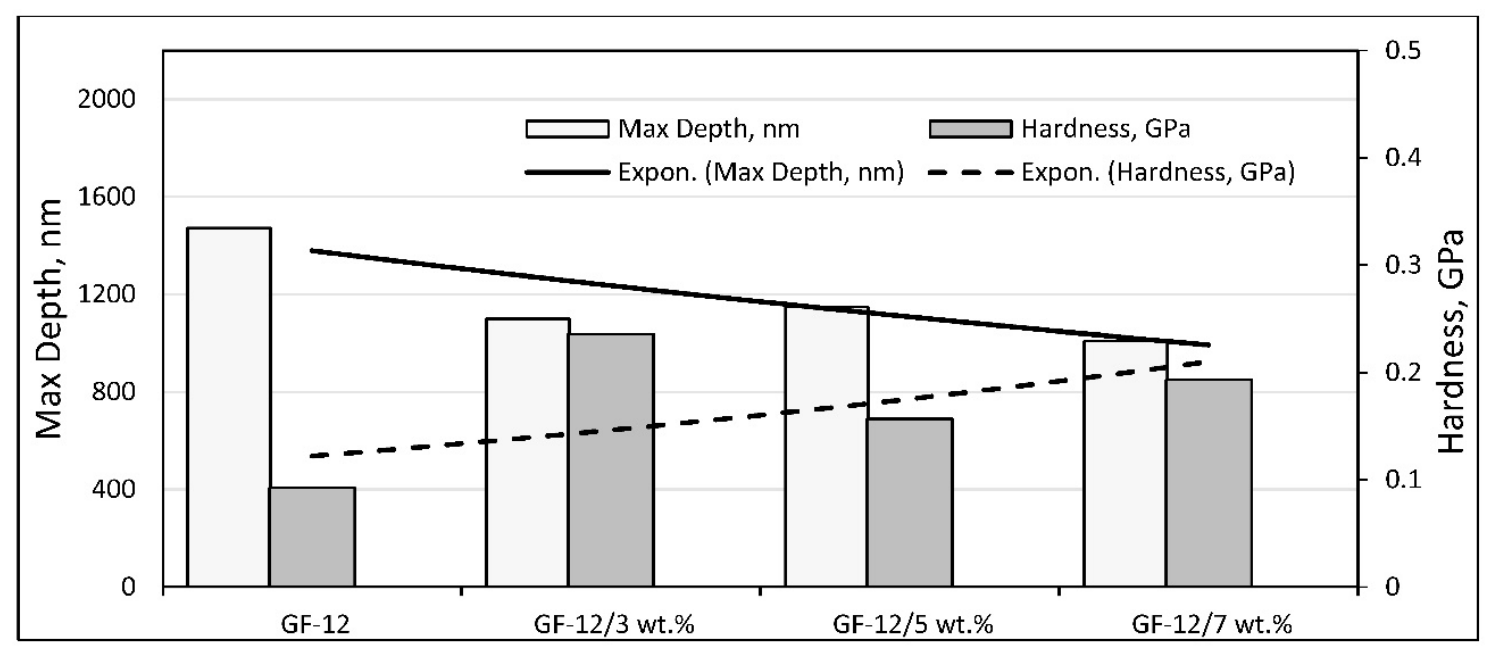

Figure 6. Maximum depth and Non-hardness of the GF-12 samples

As expected, the addition of layered silicates into the recycled GF-12 had a marked effect on the nanohardness. The nanohardness for the GF-12 nanocomposite samples increased with the increased content of the layered silicates (up to 7 wt.\%). Nanohardness values showed the ability of the material to resist plastic deformation. Unlike the unreinforced GF-12 sample, all GF-12/nanocomposite systems showed more internal obstruction due to the presence of layered silicates.

The reduced modulus measured for recycled GF-12 was 1.28744 GPa. For 3\%, 5\% and 7 wt. \% clay loaded samples, the reduced moduli were 2.95051 (an approximately 129\% increase), 2.08470 (an approximately 62\% increase) and $2.96331 \mathrm{GPa}$ (an approximately 130\% increase), respectively. By using Equation 3 the theoretical elastic modulus values were calculated, as shown in Table 3. The calculated elastic modulus for unreinforced GF-12 is $1.2373 \mathrm{GPa}$, and for the $3 \mathrm{wt}$ \% of clay loaded sample is $2.8397 \mathrm{GPa}$. For $5 \%$ and $7 \mathrm{wt}$ \% of clay loaded samples, the elastic moduli were 2.0049 and $2.8521 \mathrm{GPa}$, respectively. Results were calculated using experimental load information for recycled GF-12 and various nanoclay reinforced samples and the results compared favorably with the practical indentation results, as shown in Figure 7. 


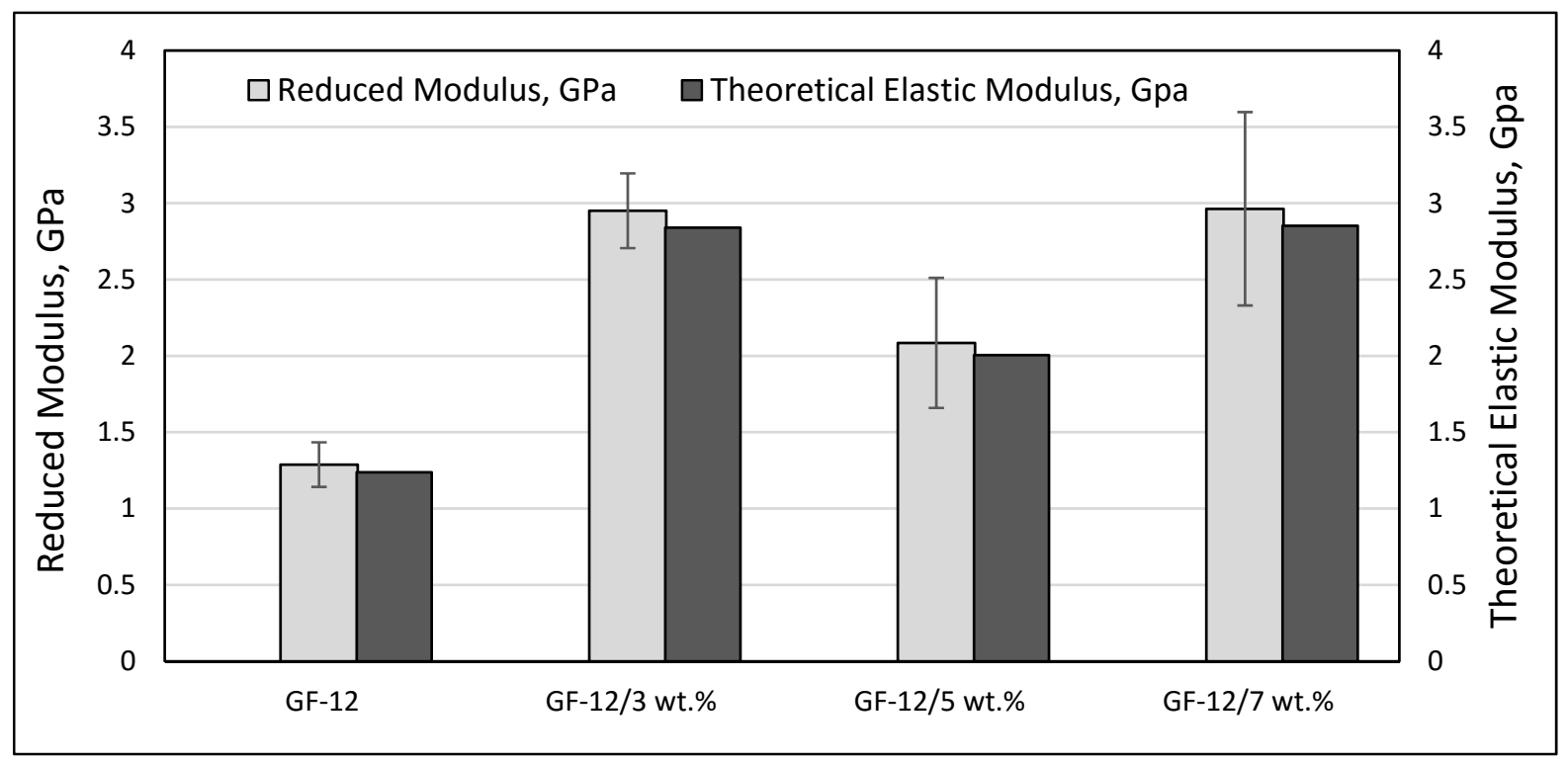

Figure 7. Experimental and theoretical reduced modulus of the GF-12 samples

The mechanisms of improvement in the nanohardness for the GF-12 matrix can be explained as the positive effect of high aspect ratio nanoclay reinforcement. The addition of the "high aspect ratio" layered silicate into GF-12 leads to an increase of hardness (decrease in indentation depth) in comparison with the neat GF-12. The nanohardness results were found to be in close agreement with the work carried out by other studies (Aldousiri et al., 2011; Dhakal, Aldousiri, Zhang, Alhubail, \& Bennett, 2015).

Table 3. Summary of nanoindentation results for GF-12 nanocomposites

\begin{tabular}{lcccc}
\hline Sample & $\begin{array}{c}\text { Max Depth } \\
(\mathrm{nm})\end{array}$ & $\begin{array}{c}\text { Hardness } \\
(\mathrm{GPa})\end{array}$ & $\begin{array}{c}\text { Reduced Modulus } \\
(\mathrm{GPa})\end{array}$ & $\begin{array}{c}\text { Theoretical Elastic Modulus } \\
(\mathrm{GPa})\end{array}$ \\
\hline GF-12 & $1472.26( \pm 129.64)$ & $0.09223( \pm 0.018)$ & $1.28744( \pm 0.146)$ & 1.2373 \\
GF-12/3 wt. $\%$ & $1099.79( \pm 429.01)$ & $0.23557( \pm 0.141)$ & $2.95051( \pm 1.873)$ & 2.8397 \\
GF-12/5 wt. $\%$ & $1147.81( \pm 132.91)$ & $0.15664( \pm 0.041)$ & $2.08470( \pm 0.426)$ & 2.0049 \\
GF-12/7 wt. $\%$ & $1007.56( \pm 116.46)$ & $0.19317( \pm 0.051)$ & $2.96331( \pm 0.633)$ & 2.8521 \\
\hline
\end{tabular}

\section{Conclusion}

This study was conducted to examine the effect of various loading levels of layered silicates reinforcement on the thermal and nanoindentation properties of GF-12 and GF-12/nanocomposites. This investigation leads to the following conclusions:

- All the GF-12/nanocomposite samples showed d-spacing values that are modestly higher than that for the unreinforced GF-12 sample.

- The addition of layered silicate to GF-12 composite led to remarkable positive effects on the penetration resistance and hardness of the nanocomposite samples. Moreover, the nanoindentation properties thus created were more sensitive to the amount of clay than the nanostructure for GF-12 and GF-12/nanocomposites.

- The improvement in the glass transition temperature up to $5 \mathrm{wt}$ \% was almost proportional to the clay loading. The further addition of layered silicate resulted in the reduction of the $\mathrm{T}_{\mathrm{g}}$. which was attributed to the intercalation level as demonstrated by XRD.

- The crystallization temperature showed an improvement from the incorporation of layered silicate compared to the base polymer. The enhancement of crystallization was attributed to the addition of clay loading, which functioned as a nucleating agent which can increase the rate of crystallization. 
- The heat scanning cycle by the DSC showed that the addition of layered silicate resulted in a slight decrease in the melting temperature, which was traced to the reduced crystallite size which was influenced by the incorporation of layered silicate in the polymer matrix.

\section{References}

Alateyah, A. I., Dhakal, H. N., \& Zhang, Z. Y. (2013). Processing, Properties, and Applications of Polymer Nanocomposites Based on Layer Silicates: A Review. Advances in Polymer Technology, 32(4), n/a-n/a. http://dx.doi.org/10.1002/adv.21368

Alateyah, A. I., Dhakal, H .N., \& Zhang, Z. Y. (2014). Water Absorption Behavior, Mechanical and Thermal Properties of Vinyl Ester Matrix Nanocomposites Based on Layered Silicate. Polymer-Plastics Technology and Engineering, 53(4), 327-343. http://dx.doi.org/10.1080/03602559.2013.844246

Aldousiri, B., Dhakal, H. N., Onuh, S., Zhang, Z. Y., \& Bennett, N. (2011). Nanoindentation behaviour of layered silicate filled spent polyamide-12 nanocomposites. Polymer Testing, 30(6), 688-692. http://dx.doi.org/10. 1016/j.polymertesting.2011.05.008

Aldousiri, B., Shalwan, A., \& Chin, C. W. (2013). A Review on Tribological Behaviour of Polymeric Composites and Future Reinforcements. Advances in Materials Science and Engineering, 2013, 8. http://dx.doi.org/ $10.1155 / 2013 / 645923$

Alexandre, M., \& Dubois, P. (2000). Polymer-layered silicate nanocomposites: preparation, properties and uses of a new class of materials. Materials Science and Engineering: R: Reports, 28(1-2), 1-63. http://dx.doi.org/10. 1016/S0927-796X(00)00012-7

Bakar, M., Kostrzewa, M., Hausnerova, B., \& Sar, K. (2010). Preparation and property evaluation of nanocomposites based on polyurethane - modified epoxy/montmorillonite systems. Advances in Polymer Technology, 29(4), 237-248. http://dx.doi.org/10.1002/adv.20192

Dhakal, H. N., Aldousiri, B., Zhang, Z. Y., Alhubail, M., \& Bennett, N. (2015). Characterization and Properties of Layered Silicate Reinforced Spent DuraForm EX Nanocomposites. Polymer-Plastics Technology and Engineering, 54(5), 484-493. http://dx.doi.org/10.1080/03602559.2014.955198

Djebara, Y., El Moumen, A., Kanit ,T., Madani, S., \& Imad, A. (2016). Modeling of the effect of particles size, particles distribution and particles number on mechanical properties of polymer-clay nano-composites: Numerical homogenization versus experimental results. Composites Part B: Engineering, 86, 135-142. http://dx.doi.org/10.1016/j.compositesb.2015.09.034

Fischer, H. (2003). Polymer nanocomposites: from fundamental research to specific applications. Materials Science and Engineering: C, 23(6-8), 763-772. http://dx.doi.org/10.1016/j.msec.2003.09.148

Giannelis, E. P. (1996). Polymer Layered Silicate Nanocomposites. Advanced Materials, 8(1), 29-35. http://dx.doi.org/10.1002/adma.19960080104

Ginzburg, V. V., Singh, C., \& Balazs, A. C. (2000). Theoretical phase diagrams of polymer/clay composites: the role of grafted organic modifiers. Macromolecules, 33(3), 1089-1099 .

Hu, Y., Shen, L., Yang, H., Wang, M., Liu, T., Liang, T., \& Zhang, J. (2006). Nanoindentation studies on Nylon 11/clay nanocomposites. Polymer Testing, 25(4), 492-497. http://dx.doi.org/10.1016/j.polymertesting. 2006.02.005

Hussain, F., Hojjati, M., Okamoto, M., \& Gorga, R. E. (2006). Review article: polymer-matrix nanocomposites, processing, manufacturing, and application: an overview. Journal of composite materials, 40(17), 1511-1575. http://dx.doi.org/10.1177/0021998306067321

Kiliaris, P., \& Papaspyrides, C. D. (2010). Polymer/layered silicate (clay) nanocomposites: An overview of flame retardancy. Progress in Polymer Science, 35(7), 902-958. http://dx.doi.org/10.1016/j.progpolymsci.2010. 03.001

Kim, J., \& Creasy, T. S. (2004). Selective laser sintering characteristics of nylon 6/clay-reinforced nanocomposite. Polymer Testing, 23(6), 629-636. http://dx.doi.org/10.1016/j.polymertesting.2004.01.014

Kotal, M., \& Bhowmick, A .K. (2015). Polymer nanocomposites from modified clays: Recent advances and challenges. Progress in Polymer Science, 51, 127-187. http://dx.doi.org/10.1016/j.progpolymsci.2015.10.001

Krishnamoorti, R., Vaia, R. A., \& Giannelis, E. P. (1996). Structure and Dynamics of Polymer-Layered Silicate Nanocomposites. Chemistry of Materials, 8(8), 1728-1734. http://dx.doi.org/10.1021/cm960127g 
Liu, T., Ping Lim, K., Chauhari Tjiu, W., Pramoda, K. P., \& Chen, Z.-K. (2003). Preparation and characterization of nylon 11/organoclay nanocomposites. Polymer, 44(12), 3529-3535. http://dx.doi.org/10.1016/S0032-3861 (03)00252-0

Pinnavaia, T. J., \& Beall, G. W. (Eds.). (2000). Polymer-clay nanocomposites. John Wiley.

Shalwan, A., \& Yousif, B. F. (2013). In State of Art: Mechanical and tribological behaviour of polymeric composites based on natural fibres. Materials \& Design, 48, 14-24. http://dx.doi.org/10.1016/j.matdes. 2012.07.014

Shalwan, A., \& Yousif, B. F. (2014). Influence of date palm fibre and graphite filler on mechanical and wear characteristics of epoxy composites. Materials \& Design, 59, 264-273. http://dx.doi.org/10.1016/j.matdes. 2014.02.066

Shen, L., Phang, I. Y., Liu, T., \& Zeng, K. (2004). Nanoindentation and morphological studies on nylon 66/organoclay nanocomposites. II. Effect of strain rate. Polymer, 45(24), 8221-8229. http://dx.doi.org/10. 1016/j.polymer.2004.09.062

Shen, L., Tjiu, W. C., \& Liu, T. (2005). Nanoindentation and morphological studies on injection-molded nylon-6 nanocomposites. Polymer, 46(25), 11969-11977.http://dx.doi.org/10.1016/j.polymer.2005.10.006

Sinha Ray, S., \& Okamoto, M. (2003). Polymer/layered silicate nanocomposites: a review from preparation to processing. Progress in Polymer Science, 28(11), 1539-1641. http://dx.doi.org/10.1016/j.progpolymsci. 2003.08.002

Thomas, S., \& Pothan, L. A. (2009). Natural fibre reinforced polymer composites from macro to nanoscale. Paris; Philadelphia (Pa): Éd. des Archives contemporaines; Old City publishing.

Yasmin, A., Luo, J. J., Abot, J. L., \& Daniel, I. M. (2006). Mechanical and thermal behavior of clay/epoxy nanocomposites. Composites Science and Technology, 66(14), 2415-2422. http://dx.doi.org/10.1016/ j.compscitech.2006.03.011

Youssef, A. M. (2013). Polymer Nanocomposites as a New Trend for Packaging Applications. Polymer-Plastics Technology and Engineering, 52(7), 635-660. http://dx.doi.org/10.1080/03602559.2012.762673

Yu, S., Zhao, J., Chen, G., Juay, Y. K., \& Yong, M. S. (2007). The characteristics of polyamide layered-silicate nanocomposites. Journal of Materials Processing Technology, 192-193, 410-414. http://dx.doi.org/10. 1016/j.jmatprotec.2007.04.006

Zeng, Q. H., Yu, A. B., Lu, G. Q., \& Paul, D. R. (2005). Clay-based polymer nanocomposites: research and commercial development. Journal of nanoscience and nanotechnology, 5(10), 1574-1592.

\section{Copyrights}

Copyright for this article is retained by the author(s), with first publication rights granted to the journal.

This is an open-access article distributed under the terms and conditions of the Creative Commons Attribution license (http://creativecommons.org/licenses/by/4.0/). 